\title{
Unfolding the ambidextrous effects of proactive and responsive market orientation
}

\author{
Dennis Herhausen \\ Assistant Professor of Marketing \\ Institute of Marketing, University of St.Gallen \\ Dufourstr. 40a, 9000 St. Gallen, Switzerland
}

Phone: +41.71 .2242859$

E-mail: dennis.herhausen@unisg.ch

The current version of the manuscript was completed in 10/2015.

The T1 data was collected between 07/2010 and 09/2010, and the T2 data was collected between 08/2012 and 10/2012.

\section{Acknowledgements}

The author is grateful to the two anonymous reviewers and the editors for their advice and suggestions during the revision process, and thanks Johannes Hattula, Petra Kipfelsberger, Luigi De Luca, Robert E. Morgan, Kirsten Mrkwicka, and Marcus Schögel for helpful comments on earlier drafts of the manuscript. The author also greatly benefitted from a Swiss National Science Foundation research grant (PBSGP1-131429). 


\title{
Unfolding the ambidextrous effects of proactive and responsive market orientation
}

\begin{abstract}
Investigating the ambidextrous effects of its proactive and responsive dimension offers a fresh perspective on market orientation. Drawing upon the ambidexterity literature, the author derives hypotheses on the joint effects of combining and balancing proactive and responsive market orientation. He examines his hypotheses with two-wave panel survey data from 167 strategic business units. Using time-lagged performance data and polynomial regression with response surface analysis to overcome limitations of previous studies of ambidexterity, the author finds that the balance between proactive and responsive market orientation has an incremental positive effect on performance beyond their combined effect; that performance will decline less sharply when proactive is higher than responsive market orientation; and that as the level of balance increases, performance will first decrease and then increase. Given resource scarcity, an important and counterintuitive implication of the present study is that balancing proactive and responsive market orientation is as important as their combination.
\end{abstract}

Keywords: market orientation; ambidexterity; resource scarcity; polynomial regression analysis 


\section{Unfolding the ambidextrous effects of proactive and responsive market orientation}

\section{Introduction}

A recurring theme in the marketing and management literature is that successful firms address not only current but also future needs of customers (e.g., Blocker et al. 2011; Ketchen et al. 2007; Narver et al. 2004). Managerial experience mirrors the academic observation, for example a statement from IBM's Global Chief Executive Officer Study: "Make sure you are providing what customers want tomorrow, instead of what they wanted yesterday" (2010, p. 47). Thus, firms need to be highly skilled at serving expressed and current needs to fulfill today's demand, while at the same time also looking to the future by creating innovations that address latent and future needs of customers (Slater and Narver 1998). In other words, firms should be ambidextrous and score high on both components of market orientation (MO): responsive MO, that is the ability to satisfy customers' current and expressed needs and associated with marketing exploitation, and proactive $M O$, that is the ability to satisfy customers' future and latent needs and associated with marketing exploration (Narver et al. 2004).

While the strategy of maximizing both proactive $\mathrm{MO}$ and responsive $\mathrm{MO}$ possesses intuitive appeal, achieving and maintaining such a strategy is extremely difficult because firms need to spend vast financial and intellectual resources to maximize both foci simultaneously (Ketchen et al. 2007). Thus, managers may have to decide on investing a given amount of resources in responsive or proactive MO, without the possibility to maximize both. Contradicting empirical results complement the theoretical tensions. For example, while Atuahene-Gima et al. (2005) find a negative effect of the interaction between proactive and responsive MO on performance, Blocker et al. (2011) find a positive interaction effect on performance. 
Despite the resources necessary, contradictions and tradeoffs might occur between proactive and responsive MO (e.g., Yannopoulos et al. 2012). While a proactive approach emphasizes the translation of customers' unexpressed and future needs into new products or services and focuses on exploration, a responsive approach emphasizes the close attention to customers' current needs and focuses on exploitation (Narver et al. 2004). The disparities led some researchers to point out the difficulties to successfully combine proactive and responsive MO (Lamore et al. 2013), or more broadly exploration and exploitation (March 1991).

Table 1 reviews previous studies and their contradicting findings on the performance implications of ambidexterity. Extant research reports both a positive effect (e.g., Cillo et al. 2010; Lubatkin et al. 2006) and negative effect (e.g., Aspara and Tikkanen 2013; Vorhies et al. 2011) of ambidexterity on performance. However, two limitations inherent in previous studies led the author question some findings. First, many studies employ a cross sectional design which suffers from simultaneity (Gatti et al. 2015). Thus, performance may potentially cause ambidexterity, and reverse causality may potentially explain some contradictions. Second, extant research employs an incomplete understanding of ambidexterity because research to date considers neither the direction of imbalance nor the level of balance between exploration and exploitation or proactive and responsive MO. Therefore, the author challenges previous approaches of measuring ambidexterity, and derives testable hypotheses on the complex joint performance effects of proactive and responsive MO.

The present research is the first study that uses response surface analysis to test for the performance effects of ambidexterity. Using two-wave panel survey data from 167 strategic business units (SBUs), the author finds that the balance between proactive and responsive MO has an incremental positive effect on performance beyond their combined effect; that performance will decline more sharply when responsive is higher than proactive MO; and that as 
the level of balance increases, performance will first decrease and then increase with an increasing rate.

The intended contribution of the present study is threefold. First, the findings from the empirical study advance the MO literature by pointing out that the relationship between proactive MO, responsive MO, and performance is more complex than previously assumed. Second, the author informs marketing and management researchers who conduct empirical investigations of ambidextrous constructs by highlighting the importance of considering lagged performance outcomes and the superiority of response surface analysis to uncover the complex joint effects of proactive and responsive MO, and of exploration and exploitation. Third, the results inform managers on how to increase the output of MO under conditions of resource scarcity.

\section{-Table 1 here-}

\section{Theoretical background}

\subsection{Proactive, responsive, and ambidextrous $M O$}

In response to criticism that being market-oriented may harm firms, Slater and Narver (1998) introduce the twin concepts of a customer-led philosophy, which deals with satisfying customers' current and expressed needs (i.e., responsive $M O$ ), and a market-oriented philosophy which deals with understanding and satisfying customers' future and latent needs (i.e., proactive $M O)$. However, the proactive and responsive dimensions of MO do not independently affect performance (Atuahene-Gima et al. 2005; Blocker et al. 2011). Thus, when evaluating the link between MO and performance, researchers should consider the joint effects of proactive and responsive MO, or in other words the ambidexterity within MO. 
Ambidexterity is an organization's ability to be aligned in managing today's business demands while simultaneously being adaptive to changes in the environment (March 1991). The most common labels for the two complementary activities are exploitation and exploration. While exploitation refers to activities that involve improving and refining current skills and procedures, exploration refers to activities that involve challenging prior approaches (March 1991). In line with the definition of ambidexterity, ambidextrous MO is an organization's ability to satisfy customers' current and expressed needs with responsive MO (i.e., exploiting customer needs) while simultaneously being able to address customers' future and latent needs with proactive MO (i.e., exploring customer needs).

\subsection{The combined and balanced view on ambidextrous MO}

Following He and Wong (2004), ambidexterity refers to two conceptually distinct views - one relates to the combination and the other relates to the balance of exploration and exploitation. Following the dual logic of ambidexterity, the present study differentiates between combined MO, a firm's efforts to increase the complementary effect of proactive and responsive $\mathrm{MO}$, and balanced MO, a firm's efforts to balance the relative emphasis on proactive and responsive MO (ct. Cao et al. 2009; He and Wong 2004). The two different views determine the assessment of ambidextrous MO. As an example, one may imagine two firms: The first firm scores medium on proactive MO and high on responsive MO (i.e., the firm overemphasizes current needs), the second firm has a medium score on both proactive and responsive MO (i.e., the firm balances current and future needs). If ambidextrous MO refers to combined MO, the former firm is more ambidextrous than the latter. However, if ambidextrous MO refers to balanced MO, the second firm is more ambidextrous than the first. Furthermore, ambidextrous 
MO corresponds to two different types of strategic fit from Venkatraman (1989): "fit as moderating" (combined MO) and "fit as matching" (balanced MO). While the "fit as moderating" test implies that proactive and responsive MO add value to each other to improve performance, the "fit as matching" test implies that a smaller absolute difference between proactive and responsive MO enhances performance.

\subsection{Prior approaches to conceptualize ambidexterity}

Until now, researchers use three approaches to conceptualize the two dimensions of ambidexterity: addition, multiplication, and absolute difference. Table 2 reviews the three approaches, illustrate the operationalization of ambidexterity, and identifies the limitations of the approaches (ct. Edwards 1994; Kim and Hsieh 2003). Addition and multiplication conceptualize the combined dimension of ambidexterity. However, both approaches have limitations because they do not determine whether exploration or exploitation contributes more to the magnitude of ambidexterity. Furthermore, they generate the same magnitude of ambidexterity for distinct firms (e.g., when using addition, a firm with exploration $=5$ and exploitation $=1$ has the same ambidexterity score as a firm with both exploration and exploitation $=3$ ). In addition, the multiplication approach may be interpreted as an interaction term to test the moderating effect between the two concepts (e.g., Atuahene-Gima et al. 2005; Blocker et al. 2011). Absolute difference conceptualizes the balanced dimension of ambidexterity. However, the absolute difference approach assumes that the direction of asymmetry does not matter (e.g., a firm with exploration $=5$ and exploitation $=3$ has the same ambidexterity score as a firm with exploration $=3$ and exploitation $=5$ ), presumes an equal proportion of positive and negative scores, and may confound the main effects of exploration and exploitation on an outcome (Edwards 1994). 
Furthermore, all three approaches prevent to test whether imbalance in one direction is more detrimental than imbalance in the other direction. In light of the limitations outlined above and in Table 2, the three approaches provide managers with insufficient insights on where to effectively invest scare resources. The author uses polynomial regression with response surface analysis to overcome the limitations and to test for the performance effects of combining and balancing proactive and responsive MO (Edwards and Parry 1993). Thus, compared to previous studies investigating the joint effects of combined and balanced ambidexterity (Cao et al. 2009; He and Wong 2004; Wei et al. 2014), the present study uses a novel conceptualization of ambidexterity which allows to capture a more complete picture of the relationship between proactive MO, responsive MO, and performance.

\section{-Table 2 here-}

\section{Hypotheses development}

\subsection{Combining proactive and responsive $\mathrm{MO}$}

Consistent with previous research (e.g., Blocker et al. 2011, Cillo et al. 2010) and the "fit as moderating" logic (Venkatraman 1989), the author expects that proactive and responsive MO can be supportive of one another and argues that each help to leverage the effects of the other. Specifically, proactive MO helps to overcome the inherent limitations of responsive MO such as the lack of breakthrough learning and the inability to adapt quickly to market shifts. On the contrary, responsive MO helps to enhance the impact of proactive MO by encouraging realism in the attempt to address new and distant customer needs. In particular, responsive MO ensures the effectiveness of proactive MO by safeguarding against undue risk taking (Jaworski et al. 2000):

\section{$\mathrm{H}_{1}$ : The total level of MO (combination of proactive and responsive MO) has a positive effect on market performance.}




\subsection{Balancing proactive and responsive $M O$}

Balanced MO is the absolute difference in the extent to which a firm pursues proactive and responsive MO. Thus, balance exists when a firm pursues both proactive and responsive MO equally (see middle of Figure 1a). Conversely, in situations of imbalance, the degree of imbalance is the absolute difference between proactive and responsive MO. In line with the "fit as matching" logic (Venkatraman 1989), the author expects that balancing proactive and responsive MO helps to achieve a dual strategy in which short-term and long-term performance orientations are in equilibrium (Jaworski et al. 2000). A firm that focuses too much on exploitation is unlikely to be effective at serving the needs of customers because the firm will not be able to uncover novel ideas (March 1991). Conversely, a firm that focuses too much on exploration suffers the costs of experimentation without gaining from its benefits because such a firm follows too many new and risky ideas. Importantly, the effect of balanced MO may go beyond the effect of combined $\mathrm{MO}$ because the combination of proactive and responsive $\mathrm{MO}$ improves performance by leveraging more complementary resources to satisfy current and future needs; here maximizing the input lead to an output maximum. On the contrary, balanced MO makes a given input more efficient, as thereby preventing over-commitment in one dimension at the expense of the other dimension (Cillo et al. 2010):

\section{$\mathrm{H}_{2}$ : The balance (imbalance) between proactive and responsive $\mathrm{MO}$ has a positive (negative) effect on market performance.}

\subsection{The direction of imbalance between proactive and responsive $M O$}

Two directions of imbalance are possible: Proactive MO may exceed responsive MO (right side of Figure 1a), or responsive MO may exceed proactive MO (left side of Figure 1a). The author expects that imbalance in one direction has different effects than imbalance in the 
opposite direction. In a mismatched situation in which responsive MO is higher than proactive MO, the firm focuses more on current needs of its customers on the expense of generating insight about evolving needs. Such a customer-led orientation is reactive and focuses on the short term, which constrains the ability to innovate (Slater and Narver 1998). Thus, such firms constantly run the risk of lagging behind on new technologies and of losing their position in the industry. In a mismatched situation in which responsive $\mathrm{MO}$ is lower than proactive $\mathrm{MO}$, performance will be impacted to a lesser extent given that superior customer value can be continually created by addressing latent and evolving needs (Blocker et al. 2011). Although such a firm is endangered of losing proximity to the current market (Jaworski et al. 2000), the firm still creates new market opportunities. Therefore, in comparison to the opposite situation where responsive MO is higher than proactive MO, superior performance can still be achieved:

\section{$\mathrm{H}_{3}$ : Market performance is lower when proactive MO is higher than responsive MO compared to when responsive MO is higher than proactive MO.}

\subsection{The level of balance between proactive and responsive $\mathrm{MO}$}

Balanced MO can occur on a continuum ranging from low to high levels of proactive and responsive MO (Figure 1b). A low level of balance does not imply imbalance, but that both proactive and responsive MO are on the same low level. The author expects that performance increases as the level of balance increases. Theoretical considerations on the two dimensions of MO (Ketchen et al. 2007) and empirical generalizations of previous research (e.g., Haugland et al. 2007; Kirca et al. 2005) support the positive relationship: Both proactive and responsive MO lead to higher innovativeness, increase a unit's responsiveness, and contribute to the creation of a positional advantage in comparison to competitors; which eventually increase performance:

\section{$\mathrm{H}_{4}$ : Market performance is higher when the level of balance between proactive and responsive MO is high compared to when the level of balance is low.}


-Figure 1 here-

\section{Methods}

\subsection{Data collection}

Data from a survey among 167 SBUs in manufacturing and service industries at two points in time separated by two years test the hypotheses. The author measures all independent and control variables at $\mathrm{T} 1$ and the dependent variable at $\mathrm{T} 2$ to make causal interferences. He used the database of a Professional Marketing Association to contact the senior manager responsible for marketing in 1,067 SBUs with an invitation to an electronic survey. After one follow-up, the author received 256 fully completed T1 questionnaires (24\% response rate). Respondents have on average nine years of experience with the SBU, and score 6.1 and 6.3 on two seven-point scales measuring the degree of knowledge about customer needs and innovation processes. F-tests reveal no significant differences between respondents and 250 nonrespondents in SBU size, SBU age, gender, and age of the respondents (all $F<.29$ ).

The author collected additional data from second respondents within the SBU. From the 256 key informants, 181 agreed to forward a link to a questionnaire including the main constructs of interest to another marketing or sales manager in their SBU. From the forwarded messages, the author received 87 usable questionnaires (48\% response rate). Key informants' assessments of MO were compared to the equivalent assessments from the second informants. The author excluded five SBUs from further analysis because their average deviation value was larger than one. For further data analysis, he averaged the responses of the two managers.

Of the 251 SBUs observed at T1, three ceased to exist at T2 because they were acquired or dissolved, and 36 managers were no longer working for their respective unit. The remaining 
212 managers were contacted via e-mail and phone call with a gift certificate incentive, and 167 of the key informants provided information on SBU market performance (79\% response rate).

\subsection{Measures}

The Appendix provides a list of measurement items for the key constructs. The scales from Narver et al. (2004) measure proactive $M O$ and responsive $M O$. The author uses polynomial regression equations (Edwards and Parry 1993) to investigate the effects of combining and balancing proactive and responsive MO. Thus he includes the simple and squared effects of proactive and responsive MO as well as the interaction between both in the analysis. The market performance scale from Slater and Narver (1994) measures average market performance over two years to reduce the impact of abnormal one-time effects, both at T1 and T2. The author includes the following controls: Marketing and R\&D expenditures relative to main competitors, market share of the participating SBU in its most important market, SBU size, SBU age, industry type, competitive intensity, and technology uncertainty.

\subsection{Measurement model}

A confirmatory factor analysis on all scales (proactive MO, responsive MO, T1 market performance, T2 market performance) shows a good fit $\left(\chi^{2}\right.$ (d.f. $)=325.02(220) ; p<.01 ; \mathrm{CFI}=$ .96 ; RMSEA = .05). During the confirmatory factor analysis, the author allowed for error covariances among the identical measures of market performance at T1 and T2 (i.e., he introduced four error covariances). An alternative model with all items loading on a common factor reveals poorer model fit $\left(\chi^{2}(\right.$ d.f. $)=1^{\prime} 629.36(226) ; p<.01 ; \mathrm{CFI}=.50 ; \mathrm{RMSEA}=.19 ; \Delta \chi 2$ 
$=1304.34, \Delta$ d.f. $=6, p<.01)$. Table 3 reports descriptive statistics, correlations, Cronbach's alpha, composite reliability, and average variance extracted for all variables.

-Table 3 here-

\section{Analysis and results}

\subsection{Analytical approach}

Polynomial regression analysis is especially well suited to analyze the extent to which combinations of two predictor variables (i.e., proactive and responsive MO) relate to an outcome, particularly in the case when balancing the two predictors is a central consideration (Edwards 1994; Roberts and Grover 2012). Furthermore, the approach allows testing whether imbalance in one direction has different effects than imbalance in the opposite direction $\left(\mathrm{H}_{3}\right)$, or whether mean-level differences appear for balance on high versus low levels of the predictors $\left(\mathrm{H}_{4}\right)$. Fortythree percent of the SBUs in the dataset indicate MO symmetry (difference between standardized scores of proactive and responsive $\mathrm{MO}$ is less than half a standard deviation), twenty-nine percent indicate $\mathrm{MO}$ asymmetry in which responsive is higher than proactive $\mathrm{MO}$, and twentyeight percent indicate $\mathrm{MO}$ asymmetry in which proactive is higher than responsive MO. Thus, exploring how symmetry and asymmetry in $\mathrm{MO}$ relate to market performance is appropriate.

\subsection{Results}

Table 4 reports the results of the polynomial regression analysis and the surface tests and Figure 2 the two-dimensional plot of the response surface along the symmetry and asymmetry lines. A positive effect of the combination of proactive and responsive $\mathrm{MO}$ on $\mathrm{T} 2$ market performance would support $\mathrm{H}_{1}$. The effect is positive and significant $\left(\mathrm{b}_{4}=.47, p<.01\right)$. A 
negative curvature of the response surface along the asymmetry line would support $\mathrm{H}_{2}$. The effect is negative and significant $\left(b_{3}-b_{4}+b_{5}=-.64, p<.01\right)$, and Figure 2A illustrates the curvilinear relationship with both variables centered at their scale midpoints. A significant positive slope and a positive lateral shift quantity along the asymmetry line would support $\mathrm{H}_{3}$. The results support the prediction of $\mathrm{H}_{3}\left(\mathrm{~b}_{1}-\mathrm{b}_{2}=.31 ; p<.10 ;\left(\mathrm{b}_{1}-\mathrm{b}_{2}\right) / 2 \times\left(\mathrm{b}_{3}-\mathrm{b}_{4}+\mathrm{b}_{5}\right)=.24\right)$. Figure 2A illustrates that the region left to the symmetry point (where proactive is lower than responsive MO) is visibly steeper than the region right to the symmetry point (where proactive is higher than responsive MO). Finally, a positive slope of the response surface along the symmetry line would support $\mathrm{H}_{4}$. The results support the prediction of $\mathrm{H}_{4}\left(\mathrm{~b}_{1}+\mathrm{b}_{2}=.31, p<.01\right)$. However, the results reveal also a significant, positive curvature along the symmetry line $\left(b_{3}+b_{4}+b_{5}=\right.$ $.30, p<.01)$. The positive curvature suggests that the performance effect of balanced MO is more complex than hypothesized. Figure 2B graphically illustrates the U-shaped relationship. T2 market performance decreases as the level of balance increases (due to its negative slope) from low-low to medium-medium. However, due to its positive curvature, T2 market performance increases as the level of balance continues to increase from medium-medium to high-high. Importantly, the symmetry line reaches its highest point at high levels of balance between proactive and responsive MO.

-Table 4 and Figure 2 here-

\subsection{Robustness checks}

Where possible, the author collected and correlated secondary performance data with the survey-based performance measure. The author was able to collect average sales growth data over the respective two years for 66 SBUs from AMADEUS, a global company database. The 
objective information and the managerial assessment of average sales growth of the SBUs are highly correlated $(\mathrm{r}=.64, p<.01)$, indicating that the managerial performance evaluations are valid. Moreover, the author replicated the data analysis with a weighted aggregation of the responses from multiple informants, with the self-assessment of competence as the weighting factor (degree of knowledge about customer needs and innovation processes). All results remain stable. In addition, the author used ease of market entry (single item with a seven-point Likert scale) as a proxy for method variance and included the proxy as a control in the regression analysis (Table 4, Model 4; ct. Yannopoulos et al. 2012). Again, all results remain stable. The author also examined the effects of all study variables on selective attrition of the sample from T1 to T2 with a logistic regression to test for potential endogeneity (Heckman 1979). The results show that the variables are poor predictors of attrition (all $p>.18$; see Table 4, Model 5), suggesting that selective attrition does not affect the longitudinal regression results.

\section{Discussion}

\subsection{Theoretical contributions}

Using polynomial regression with response surface analysis to overcome limitations of previous conceptualizations of ambidexterity and a lagged performance measure, the present study advances both the MO literature and the literature on ambidexterity. The results from analyzing 167 SBUs in manufacturing and service industries at two points in time suggest that the relationship between proactive $\mathrm{MO}$, responsive $\mathrm{MO}$, and performance is more complex than previously assumed. In particular, the author provides novel and surprising insights in finding (1) that the balance between proactive and responsive MO has an incremental positive effect on performance beyond their combined effect; (2) that performance will decline less sharply when 
proactive is higher than responsive $\mathrm{MO}$ as compared to the opposite; and (3) that as the level of balance increases, performance will first decrease and then increase with an increasing rate.

The first finding points out that a smaller absolute difference between proactive and responsive $\mathrm{MO}$ will enhance performance through the mitigation of risks stemming from the overcommitment to one or the other. Moreover, the incremental effect indicates that the balance between proactive and responsive $\mathrm{MO}$ is able to explain previously unaccounted variance in research on the performance effects of MO. The second finding points out that the downstream consequences associated with a mismatch in $\mathrm{MO}$ are more severe when the level of responsive MO exceed that of proactive MO. While a firm low on responsive MO may still create new market opportunities and therefore suffers less from the mismatch, a firm low on proactive MO is likely to lag behind competition. Surprisingly, the third finding suggests that firms do not always benefit from balancing proactive and responsive MO. A balance at low levels does not contribute to superior performance. A potential explanation might be that until the level reaches a certain threshold (level of balance $=3.47$ ), increasing the level of balance is only the cost of doing business and a failure preventer without performance enhancing effects (Kumar et al. 2011). When balance surpasses the threshold, the level of balance has an increasing positive performance effect. Thus, firms that continue to invest in both facets of MO are able to achieve an advantage in comparison to competitors once they overcome a critical point.

From a methodological point of view, the present research is the first study which uses polynomial regression with response surface analysis to test for the consequences of ambidextrous MO. The theoretical considerations and results of the present study illustrate that researchers are not able to fully explain the effects of proactive and responsive MO by examining only their combination or absolute difference. In a similar way, polynomial regression with response surface analysis may help to overcome limitations of previous operationalization of 
ambidexterity (see Table 2). For example, knowledge is missing regarding which activity (exploration or exploitation) contributes more to the magnitude of ambidexterity, or whether the direction of asymmetry in the exploration-exploitation relationship matters. Thus, researchers who conduct further empirical investigations of ambidexterity should use response surface analysis to uncover more complex joint effects of exploration and exploitation.

Moreover, the present research contributes to the question of whether combining proactive and responsive MO as well as combining exploration and exploitation has a positive or negative effect on performance outcomes. Table 1 reveals that extant research reports both positive effects (e.g., Cillo et al. 2010; Lubatkin et al. 2006) and negative effects (e.g., AtuaheneGima et al. 2005; Vorhies et al. 2011). However, the present study and other studies that used a lagged performance measure indicate positive effects of combined ambidexterity, suggesting that simultaneity in the cross sectional studies may account for the observed negative effects of combined ambidexterity. Thus, researchers who conduct further empirical investigations of ambidexterity should use lagged measures for dependent variables or employ other techniques to control for endogeneity issues (e.g., Gatti et al. 2015).

\subsection{Managerial contributions}

The key difference to previous conceptualizations of MO is that the present study proposes a different view on the joint effects of proactive and responsive MO, which allows managers to increase the output of MO under conditions of resource scarcity. One possibility to achieve a competitive advantage is to maximize the complementarity of proactive and responsive MO. Ketchen et al. (2007) describe such a strategy and use Pfizer and other major pharmaceuticals as examples for firms that not only address a wide array of current health issues 
and thus maximize responsive $\mathrm{MO}$, but also invest huge resources into anticipating what therapies will be needed in the future to maximize proactive MO.

However, the maximization approach is very resource intensive. A promising alternative is to balance proactive and responsive MO. Here, contrary to managerial wisdom, increasing the level of proactive or responsive MO alone may decrease the competitive advantage if the imbalance is amplified. As managers should avoid too much attention to current customer needs to the exclusion of future needs (and vice versa), reducing the overemphasis on current or future needs may be valuable. Thus, managers should become more explicitly aware of the need to balance proactive and responsive MO. For example, the German automotive manufacturers BMW, Mercedes-Benz, and Volkswagen rather strive to maximize their technological orientation and not their MO. Nevertheless, they all operate think tanks located in Silicon Valley (Douglas 2015 ) to infuse customers' latent and future needs into their core business, to reduce an overemphasis on current needs of car owners, and hence to ensure that their responsive MO is balanced with proactive MO. However, managers should be aware that investments into balanced MO only pay off once the level of balance exceeds a certain threshold.

In the present sample, the mean for proactive MO (4.49) is significantly lower than the mean for responsive MO $(4.99 ; t=6.75, p<.01)$. The difference suggests that in practice, managers may often have to increase proactive MO in order to achieve balanced MO. The managerial advice to increase proactive $\mathrm{MO}$ is underscored by the finding that imbalance in favor of responsive MO is especially detrimental for firms. The video rental chain Blockbuster provides a stunning example for such a situation (Gandel 2010). At its peak in 2004, Blockbuster had 60,000 employees, over 9,000 stores in 18 countries, and experienced high customer satisfaction rates. However, the company focused too much on the current needs of its video rental shops customers. Smaller rivals like Netflix and Redbox successfully identified upcoming 
latent and future needs like streaming and video on demand, while Blockbuster failed to do so and finally filed for bankruptcy in 2010. Managers could use empathic design (to disclose usage situations that are inconvenient yet so habitual that users are not even conscious of in order to uncover latent needs) or lead-user processes (to collect information from lead users who may have needs months or years before the mass market) to ensure sufficient focus on latent and future needs (Slater and Mohr 2006), and to avoid an imbalance in MO.

\subsection{Limitations and future research}

The present study is not without limitations, which also suggest promising avenues for future research. First, the author tests the theoretical model by analyzing data collected from SBUs in a highly developed, de-regulated market with strong competition. Thus, any inferences can only be made to to comparable SBUs in similar markets. Additional studies should replicate the analyses for different environmental conditions because the MO-performance relationship may vary across environments (e.g., Dibrell et al. 2011). Second, a nomological network of ambidextrous MO should include not only consequences but also antecedents. Future research might identify antecedents of combined and balanced MO, such as structural mechanisms, contextual features, or leadership-based solutions that resolve the tensions between proactive and responsive MO. Third, the present study does not examine which strategic action or competitive advantage may lead from the two facets of MO to the outcome (Ketchen et al. 2007). Analyzing such pathways may yield deeper insights into the concrete process how balanced and combined MO affect performance outcomes, and thus would be a fruitful avenue for future research. 


\section{REFERENCES}

Aspara, J., \& Tikkanen, H. (2013). Creating novel consumer value vs. capturing value: Strategic emphases and financial performance implications. Journal of Business Research, 66(5), 593-602.

Atuahene-Gima, K., Slater, S.F., \& Olson, E. (2005). The contingent value of responsive and proactive market orientations for new product program performance. Journal of Product Innovation Management, 22(6), 464-482.

Blocker, C.P., Flint, D.J., Myers, M.B., \& Slater, S.F. (2011). Proactive customer orientation and its role for creating customer value in global markets. Journal of the Academy of Marketing Science, 39(2), 216-233.

Cao, Q., Gedajlovic, E., \& Zhang, H. (2009). Unpacking organizational ambidexterity: Dimensions, contingencies, and synergistic effects. Organization Science, 20(4), 781-796.

Cillo, P., De Luca, L.M., \& Troilo, G. (2010). Market information approaches, product innovativeness, and firm performance: An empirical study in the fashion industry. Research Policy, 39(9), 1242-1252.

Dibrell, C., Craig, J. B., \& Hansen, E. N. (2011). How managerial attitudes toward the natural environment affect market orientation and innovation. Journal of Business Research, 64(4), 401-407.

Douglas, B. (2015). Silicon valley's automotive epicenter. The Spin of Silicon Valley. Available at: http://www.svmagazine.net/auto-epicenter/ [October 8, 2015].

Edwards, J.R. (1994). The study of congruence in organizational behavior research: Critique and a proposed alternative. Organizational Behavior and Human Decision Processes, 58(1), 51100. 
Edwards, J.R., \& Parry, M.E. (1993). On the use of polynomial regression equations as an alternative to difference scores in organizational research. Academy of Management Journal, 36(6), 1577-1613.

Gandel, S. (2010). How Blockbuster failed at failing. Time Magazine. Available at: http://content.time.com/time/magazine/article/0,9171,2022624,00.html [October 8, 2015].

Gatti, C., Volpe, L., \& Vagnani, G. (2015). Interdependence among productive activities: Implications for exploration and exploitation. Journal of Business Research, 68(3), 711-722.

Haugland, S. A., Myrtveit, I., \& Nygaard, A. (2007). Market orientation and performance in the service industry: A data envelopment analysis. Journal of Business Research, 60(11), 11911197.

He, Z., \& Wong, P.-K. (2004). Exploration vs. exploitation: An empirical test of ambidexterity. Organization Science, 15(4), 481-494.

Heckman, J. J. (1979). Sample selection bias as a specification error. Econometrica: Journal of the Econometric Society, 47(1), 153-161.

Ho, H.D, \& Lu, R. (2015). Performance implications of marketing exploitation and exploration: Moderating role of supplier collaboration. Journal of Business Research, 68(5), 10261034.

IBM (2010). Insights from the Global Chief Executive Officer Study. Retrieved January 07, 2014 from http://www.ibm.com/services/us/ceo/ceostudy2010

Jansen, J. J., Tempelaar, M. P., Van den Bosch, F. A., \& Volberda, H. W. (2009). Structural differentiation and ambidexterity: The mediating role of integration mechanisms. Organization Science, 20(4), 797-811.

Jaworski, B., Kohli, A.K., \& Sahay, A. (2000). Market-driven versus market-driving. Journal of the Academy of Marketing Science, 28(1), 45-54. 
Junni, P., Sarala, R. M., Taras, V., \& Tarba, S. Y. (2013). Organizational ambidexterity and performance: A meta-analysis. Academy of Management Perspectives, 27(4), 299-312.

Ketchen, D.J., Hult, G.T.M., \& Slater, S.F. (2007). Toward greater understanding of market orientation and the resource-based view. Strategic Management Journal, 28, 961-964.

Kirca, A., Jayachandran, S., \& Bearden, W. (2005).Market orientation: A meta-analytic review and assessment of its antecedents and impact on performance. Journal of Marketing, 69(2), $24-41$.

Kim, S. K., \& Hsieh, P. H. (2003). Interdependence and its consequences in distributor-supplier relationships: A distributor perspective through response surface approach. Journal of Marketing Research, 40(1), 101-112.

Kumar, V., Jones, E., Venkatesan, R., \& Leone, R.P. (2011). Is market orientation a source of sustainable competitive advantage or simply the cost of competing? Journal of Marketing, 75(1), 16-30.

Kumar, N., Scheer, L. K., \& Steenkamp, J. B. E. (1995). The effects of perceived interdependence on dealer attitudes. Journal of Marketing Research, 32(3), 348-356.

Lamore, P.R., Berkowitz, D., \& Farrington, P.A. (2013). Proactive/responsive market orientation and marketing — research and development integration. Journal of Product Innovation Management, 30(4), 695-711.

Lubatkin, M. H., Simsek, Z., Ling, Y., \& Veiga, J. F. (2006). Ambidexterity and performance in small-to medium-sized firms: The pivotal role of top management team behavioral integration. Journal of Management, 32(5), 646-672.

March, J.G. (1991). Exploration and exploitation in organizational learning. Organization Science, 2(1), 71-87.

Narver, J.C., Slater, S.F., \& MacLachlan, D. (2004). Responsive and proactive market orientation and new-product success. Journal of Product Innovation Management, 21(5), 334-347. 
Roberts, N., \& Grover, V. (2012). Investigating firm's customer agility and firm performance: The importance of aligning sense and respond capabilities. Journal of Business Research, 65(5), 579-585.

Slater, S. F., \& Mohr, J. J. (2006). Successful development and commercialization of technological innovation: insights based on strategy type. Journal of Product Innovation Management, 23(1), 26-33.

Slater, S.F., \& Narver, J. C. (1994). Does competitive environment moderate the market orientation-performance relationship? Journal of Marketing, 58(1), 46-55.

Slater, S.F., \& Narver, J.C. (1998). Customer led and market-oriented: Let's not confuse the two. Strategic Management Journal, 19(10), 1001-1006.

Uotila, J., Maula, M., Keil, T., \& Zahra, S. A. (2009). Exploration, exploitation, and financial performance: analysis of S\&P 500 corporations. Strategic Management Journal, 30(2), 221231.

Venkatraman, N. (1989). The concept of fit in strategy research: Toward verbal and statistical correspondence. Academy of Management Review, 14(3), 423-444.

Vorhies, D. W., Orr, L. M., \& Bush, V. D. (2011). Improving customer-focused marketing capabilities and firm financial performance via marketing exploration and exploitation. Journal of the Academy of Marketing Science, 39(5), 736-756.

Wei, Z., Yi, Y., \& Guo, H. (2014). Organizational learning ambidexterity, strategic flexibility, and new product development. Journal of Product Innovation Management, 31(4), 832-847.

Yannopoulos, P., Auh, S., \& Menguc, B. (2012). Achieving fit between learning and market orientation: Implications for new product performance. Journal of Product Innovation Management, 29(4), 531-545. 
TABLE 1

Previous empirical studies on the performance implications of ambidexterity

\begin{tabular}{|c|c|c|c|c|c|c|}
\hline \multirow[b]{2}{*}{ Study } & \multicolumn{4}{|c|}{ Approach to Ambidexterity } & \multirow{2}{*}{$\begin{array}{l}\text { Lagged } \\
\text { Outcome }\end{array}$} & \multirow[b]{2}{*}{ Key Findings } \\
\hline & Combination & Balance & $\begin{array}{l}\text { Direction of } \\
\text { Imbalance }\end{array}$ & $\begin{array}{l}\text { Level of } \\
\text { Balance }\end{array}$ & & \\
\hline \multicolumn{7}{|c|}{ Empirical studies on ambidexterity in terms of exploration and exploitation } \\
\hline He and Wong (2004) & $\checkmark$ & $\checkmark$ & & & & $\begin{array}{l}\text { Combined ambidexterity and balanced ambidexterity both have positive } \\
\text { effects on the sales growth rate. }\end{array}$ \\
\hline Lubatkin et al. (2006) & $\checkmark$ & & & & $\checkmark$ & $\begin{array}{l}\text { The combination of exploration and exploitation has a positive effect on } \\
\text { firm performance. }\end{array}$ \\
\hline Cao et al. (2009) & $\checkmark$ & $\checkmark$ & & & & $\begin{array}{l}\text { Combined ambidexterity has a positive effect and balanced ambidexterity } \\
\text { has no significant effect on firm performance. }\end{array}$ \\
\hline Uotila et al. (2009) & & $\checkmark$ & & & $\checkmark$ & $\begin{array}{l}\text { Balancing exploration and exploitation has an inverse } U \text {-shaped effect on } \\
\text { firm performance. }\end{array}$ \\
\hline Vorhies et al. (2011) & $\checkmark$ & & & & & $\begin{array}{l}\text { The combination of marketing exploitation and marketing exploration has } \\
\text { a negative effect on customer-focused marketing capabilities. }\end{array}$ \\
\hline Wei et al. (2014) & $\checkmark$ & $\checkmark$ & & & & $\begin{array}{l}\text { Combined ambidexterity has a positive effect and balanced ambidexterity } \\
\text { has an inverse } U \text {-shaped effect on new product development. }\end{array}$ \\
\hline Ho and $\mathrm{Lu}(2015)$ & $\checkmark$ & & & & & $\begin{array}{l}\text { The combination of marketing exploitation and marketing exploration has } \\
\text { a negative effect on market performance. }\end{array}$ \\
\hline \multicolumn{7}{|c|}{ Empirical studies on ambidextrous $\mathrm{MO}$} \\
\hline $\begin{array}{l}\text { Atuahene-Gima et al. } \\
(2005)\end{array}$ & $\checkmark$ & & & & & $\begin{array}{l}\text { The combination of proactive and responsive MO has a negative effect on } \\
\text { new product program performance. }\end{array}$ \\
\hline Cillo et al. (2010) & $\checkmark$ & & & & $\checkmark$ & $\begin{array}{l}\text { The combination of retrospective and forward-looking approaches to } \\
\text { market information has a positive effect on firm performance. }\end{array}$ \\
\hline Blocker et al. (2011) & $\checkmark$ & & & & & $\begin{array}{l}\text { The combination of proactive and responsive customer orientations has a } \\
\text { positive effect on customer value perceptions. }\end{array}$ \\
\hline $\begin{array}{l}\text { Aspara and Tikkanen } \\
(2013)\end{array}$ & $\checkmark$ & & & & & $\begin{array}{l}\text { The combination of novel consumer value creation and value capture has a } \\
\text { negative effect on firm financial performance. }\end{array}$ \\
\hline The present study & $\checkmark$ & $\checkmark$ & $\checkmark$ & $\checkmark$ & $\checkmark$ & $\begin{array}{l}\text { The balance between proactive and responsive MO has an } \\
\text { incremental positive effect on performance beyond their combined } \\
\text { positive effect; performance declines less sharply when proactive is } \\
\text { higher than responsive MO; and as the level of balance increases, } \\
\text { performance first decreases and then increases with an increasing rate. }\end{array}$ \\
\hline
\end{tabular}

Note: Due to space restrictions, Table 1 reports selected studies on ambidexterity in terms of exploration and exploitation. Junni et al. (2013) provide a comprehensive summary of the performance implications of organizational ambidexterity. $\mathrm{MO}=$ market orientation. 
TABLE 2

Previous approaches to conceptualize ambidexterity

\begin{tabular}{|c|c|c|c|}
\hline Approach & Operationalization & Sample studies & Limitations to conceptualize ambidextrous MO \\
\hline $\begin{array}{l}\text { Addition } \\
\text { (Combined } M O)\end{array}$ & $\begin{array}{l}\text { Exploration + Exploitation } \\
(\text { Proactive + Responsive MO })\end{array}$ & $\begin{array}{l}\text { - Jansen et al. } 2009 \\
\text { - Lubatkin et al. } 2006\end{array}$ & $\begin{array}{l}\text { The addition approach: } \\
\text { - does not determine whether proactive or responsive MO contributes } \\
\text { more to the magnitude of ambidexterity. } \\
\text { - generates the same magnitude of ambidextrous MO for distinct firms. }\end{array}$ \\
\hline $\begin{array}{l}\text { Multiplication } \\
\text { (Combined } M O)\end{array}$ & $\begin{array}{l}\text { Exploration } \times \text { Exploitation } \\
(\text { Proactive } \times \text { Responsive } M O)\end{array}$ & $\begin{array}{l}\text { - Cao et al. } 2009 \\
\text { - He and Wong } 2004 \\
\text { - Ho and Lu } 2015 \\
\text { - Vorhies et al. } 2011\end{array}$ & $\begin{array}{l}\text { The multiplication approach: } \\
\text { - does not determine whether proactive or responsive MO contributes } \\
\text { more to the magnitude of ambidextrous MO. } \\
\text { - generates the same magnitude of ambidextrous MO for distinct firms. } \\
\text { - may be interpreted as an interaction term, which tests the moderating } \\
\text { effect between proactive and responsive MO. }\end{array}$ \\
\hline $\begin{array}{l}\text { Absolute Difference } \\
\text { (Balanced } M O)\end{array}$ & $\begin{array}{l}\text { [Exploration - Exploitation] } \\
\text { ([Proactive - Responsive MO]) }\end{array}$ & $\begin{array}{l}\text { - Cao et al. } 2009 \\
\text { - He and Wong } 2004\end{array}$ & $\begin{array}{l}\text { The absolute difference approach: } \\
\text { - assumes that the direction of asymmetry between proactive and } \\
\text { responsive MO does not matter. } \\
\text { - presumes an equal proportion of positive and negative scores. } \\
\text { - confounds the main effects of proactive and responsive MO. } \\
\text { - prevents to test whether imbalance in one direction is more detrimental } \\
\text { than imbalance in the other direction. }\end{array}$ \\
\hline
\end{tabular}

Note: The overview of operationalizations is based on Cao et al. (2009) and He and Wong (2004). The limitations of the previous operationalizations are based on Edwards (1994) and Kim and Hsieh (2003). MO = market orientation.

${ }^{a}$ Spline regression allows to examine the effects of the direction of imbalance, and mean centering alleviates the problem of confounds with main effects (Kumar et al. 1995). The author thanks an anonymous reviewer for the clarification. 
TABLE 3

Descriptive statistics and correlations

\begin{tabular}{|c|c|c|c|c|c|c|c|c|c|c|c|c|c|c|}
\hline \multicolumn{2}{|c|}{ Variables } & \multirow{2}{*}{$\begin{array}{c}\mathbf{1} \\
.53\end{array}$} & \multirow[t]{2}{*}{2} & \multirow[t]{2}{*}{3} & \multirow[t]{2}{*}{4} & \multirow[t]{2}{*}{5} & \multirow[t]{2}{*}{6} & \multirow[t]{2}{*}{7} & \multirow[t]{2}{*}{8} & \multirow[t]{2}{*}{9} & \multirow[t]{2}{*}{10} & \multirow[t]{2}{*}{11} & \multirow[t]{2}{*}{12} & \multirow[t]{2}{*}{13} \\
\hline 1. & Proactive market orientation & & & & & & & & & & & & & \\
\hline 2. & Responsive market orientation & .49 & .68 & & & & & & & & & & & \\
\hline 3. & Marketing expenditure & .07 & -.10 & - & & & & & & & & & & \\
\hline 4. & R\&D expenditure & .19 & .00 & .42 & - & & & & & & & & & \\
\hline 5. & Market share & .11 & .01 & .31 & .27 & - & & & & & & & & \\
\hline 6. & SBU size $(\log )$ & .18 & -.03 & .16 & .22 & .35 & - & & & & & & & \\
\hline 7. & SBU age $(\log )$ & .03 & -.05 & .04 & .08 & .23 & .13 & - & & & & & & \\
\hline 8. & Business-to-business dummy & .05 & .14 & -.16 & -.14 & -.11 & -.21 & -.17 & - & & & & & \\
\hline 9. & Competitive intensity & -.05 & -.01 & -.08 & -.23 & -.03 & .02 & .13 & -.01 & - & & & & \\
\hline 10. & Technology uncertainty & -.03 & .06 & -.11 & -.15 & -.04 & -.15 & .13 & -.04 & .09 & - & & & \\
\hline 11. & T1 market performance & .30 & .33 & .13 & .13 & .28 & .26 & .06 & -.08 & .00 & -.01 & .78 & & \\
\hline 12. & T2 market performance & .38 & .29 & .19 & .22 & .13 & .14 & -.08 & .03 & -.13 & -.16 & .45 & .81 & \\
\hline 13. & CMV marker (ease of market entry) & .00 & -.03 & -.06 & -.11 & -.04 & .09 & -.09 & -.14 & .10 & -.12 & .06 & .02 & - \\
\hline \multicolumn{2}{|c|}{ Mean } & 4.49 & 4.99 & 3.20 & 3.24 & 4.50 & 2.57 & 1.14 & .48 & 4.01 & 2.82 & 3.88 & 4.19 & 3.90 \\
\hline \multicolumn{2}{|c|}{ Standard deviation } & .93 & .98 & 1.26 & 1.38 & 1.96 & 1.31 & .51 & .50 & .96 & .96 & 1.01 & 1.30 & 1.71 \\
\hline \multicolumn{2}{|c|}{ Cronbach's alpha } & .87 & .92 & - & - & - & - & - & - & - & - & .89 & .92 & - \\
\hline \multicolumn{2}{|c|}{ Composite reliability } & .89 & .94 & - & - & - & - & - & - & - & - & .91 & .94 & - \\
\hline
\end{tabular}

Note: Correlations of SBUs participating at T1 and T2. $\mathrm{n}=167,|\mathrm{r}| \geq .15$ is significant at $p<.05$ and $|\mathrm{r}| \geq .21$ is significant at $p<.01$; two-tailed tests. Average variance extracted is on the diagonal. $\mathrm{CMV}=$ common method variance. 
TABLE 4

Longitudinal regression analyses

\begin{tabular}{|c|c|c|c|c|c|}
\hline \multirow[b]{2}{*}{ Variable } & \multicolumn{4}{|c|}{ T2 Market Performance } & \multirow{2}{*}{$\begin{array}{c}\text { T2 Attrition } \\
\text { Model } 5\end{array}$} \\
\hline & Model 1 & Model 2 & Model 3 & Model 4 & \\
\hline Intercept & $2.42 * *$ & 1.13 & $1.28 \dagger$ & 1.19 & -.75 \\
\hline \multicolumn{6}{|l|}{ Controls } \\
\hline Marketing expenditure & .09 & .10 & .07 & .07 & .09 \\
\hline R\&D expenditure & .11 & .07 & .02 & .02 & .11 \\
\hline Market share & -.02 & -.01 & -.03 & -.03 & .03 \\
\hline SBU size $(\log )$ & .01 & -.01 & .02 & .02 & .06 \\
\hline SBU age $(\log )$ & -.19 & -.19 & -.22 & -.21 & .27 \\
\hline Business-to-business dummy & .20 & .10 & .16 & .17 & -.08 \\
\hline Competitive intensity & -.10 & -.10 & -.04 & -.04 & .13 \\
\hline Technology uncertainty & -.15 & $-.16 \dagger$ & -.12 & -.11 & .06 \\
\hline T1 market performance & $.56 * *$ & $.45^{* *}$ & $.49 * *$ & $.49 * *$ & -.21 \\
\hline \multicolumn{6}{|l|}{ Market orientation } \\
\hline Proactive MO $\left(b_{1}\right)$ & & $.30 * *$ & $.31 * *$ & $.31 * *$ & -.22 \\
\hline Responsive $\mathrm{MO}\left(b_{2}\right)$ & & .10 & .00 & .00 & .24 \\
\hline$(\text { Proactive MO })^{2}\left(b_{3}\right)$ & & & .07 & .07 & .11 \\
\hline Proactive $\mathrm{MO} \times$ responsive $\mathrm{MO}\left(b_{4}\right)$ & & & $.47 * *$ & $.47 * *$ & -.30 \\
\hline$(\text { Responsive } \mathrm{MO})^{2}\left(b_{5}\right)$ & & & $-.23 * *$ & $-.23 * *$ & .15 \\
\hline CMV marker (ease of market entry) & & & & .02 & \\
\hline $\mathrm{R}^{2}$ & .27 & .33 & .44 & .44 & $.04^{\mathrm{b}}$ \\
\hline F-value & $6.34 * *$ & $6.79 * *$ & $8.42 * *$ & $7.82 * *$ & \\
\hline$\Delta \mathrm{R}^{2}$ & & .06 & .11 & .00 & \\
\hline F-change & & $6.71 * *$ & $6.82 * *$ & .14 & \\
\hline $\mathrm{N}$ & 167 & 167 & 167 & 167 & 251 \\
\hline \multicolumn{6}{|l|}{ Surface tests } \\
\hline Slope symmetry line $\left(b_{1}+b_{2}\right)$ & & & $.31 * *$ & $.31 * *$ & \\
\hline Curvature symmetry line $\left(b_{3}+b_{4}+b_{5}\right)$ & & & $.30 * *$ & $.30 * *$ & \\
\hline Slope asymmetry line $\left(b_{1}-b_{2}\right)$ & & & $.31 \dagger$ & $.31 \dagger$ & \\
\hline Curvature asymmetry line $\left(b_{3}-b_{4}+b_{5}\right.$ & & & $-.64 * *$ & $-.64 * *$ & \\
\hline Lateral shift quantity $\left(b_{2}-b_{1}\right) /\left[2 \times\left(b_{3}\right]\right.$ & $\left.\left.{ }_{4}+b_{5}\right)\right]$ & & $.24^{\mathrm{a}}$ & $.24^{\mathrm{a}}$ & \\
\hline
\end{tabular}

Note: $* * p<.01, * p<.05, \dagger p<.10$; two-tailed tests. $\mathrm{MO}=$ market orientation; $\mathrm{CMV}=$ common method variance.

${ }^{a}$ Significance of the quantity of lateral shift is not formally tested (Edwards and Parry 1993).

${ }^{\mathrm{b}}$ Cox and Snell $\mathrm{R}^{2}$. 
FIGURE 1

\section{Expected performance effects of ambidextrous market orientation}

Panel A: Expected performance effects of balancing proactive and responsive market orientation $\left(\mathrm{H}_{2}\right)$ and of the direction of imbalance between proactive and responsive market orientation $\left(\mathrm{H}_{3}\right)$

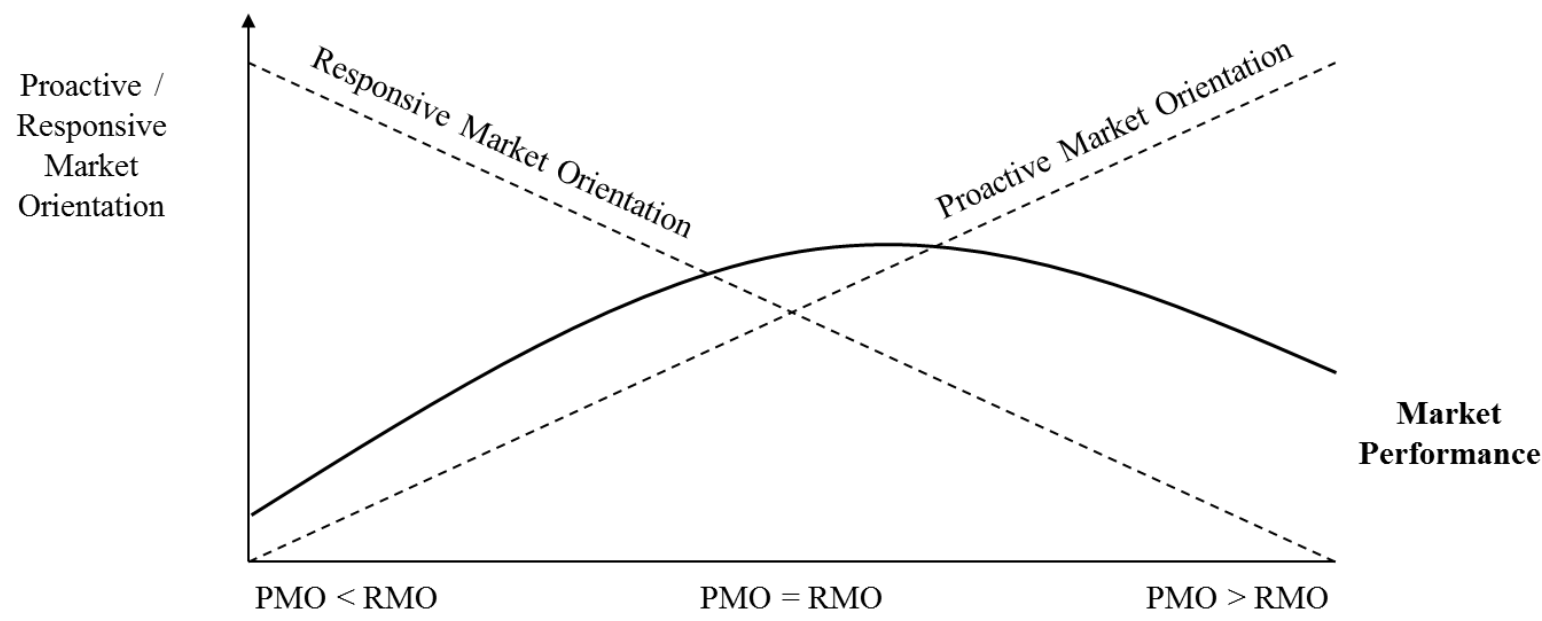

Panel B: Expected performance effect of the level of the balance between proactive and responsive market orientation $\left(\mathrm{H}_{4}\right)$

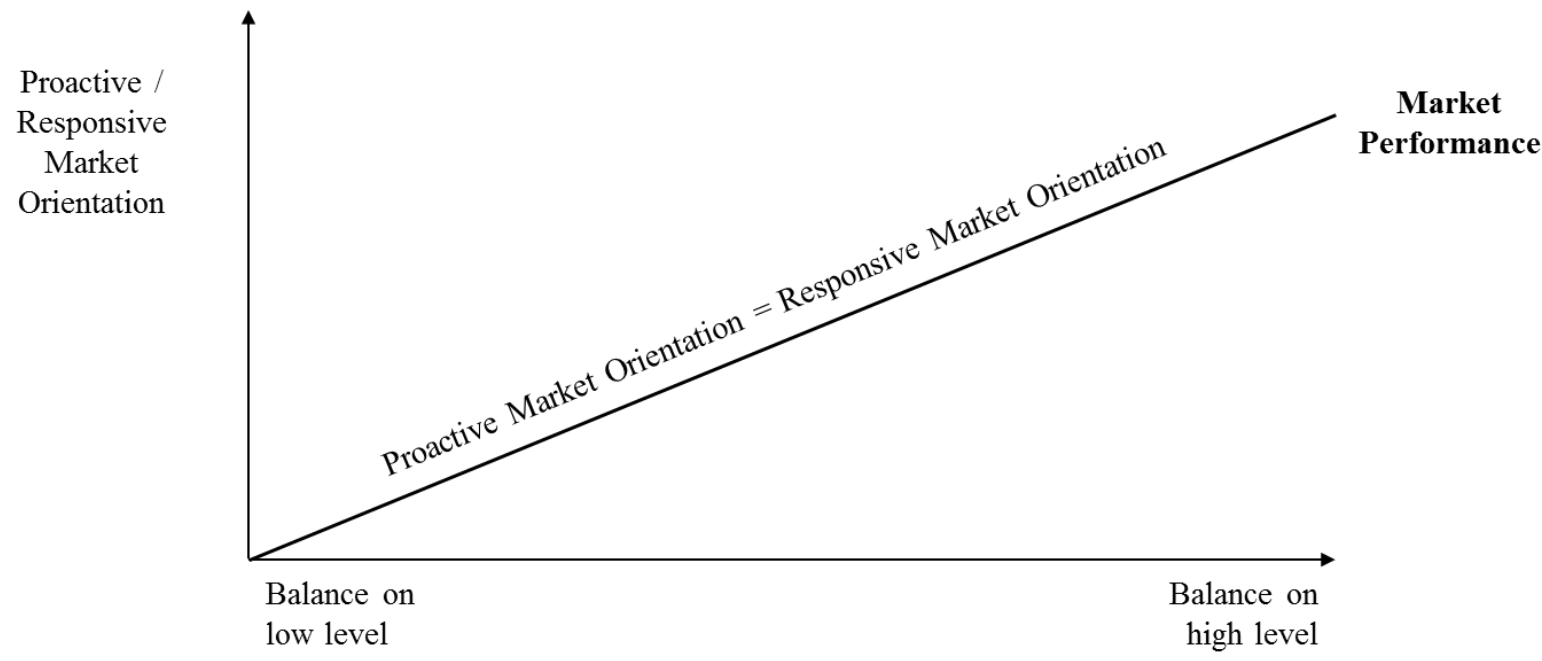

Note $: \mathrm{PMO}=$ proactive market orientation, $\mathrm{RMO}=$ responsive market orientation. 
FIGURE 2

Two-dimensional figures of the response surface plot

Panel A: Shape of the response surface along the asymmetry line

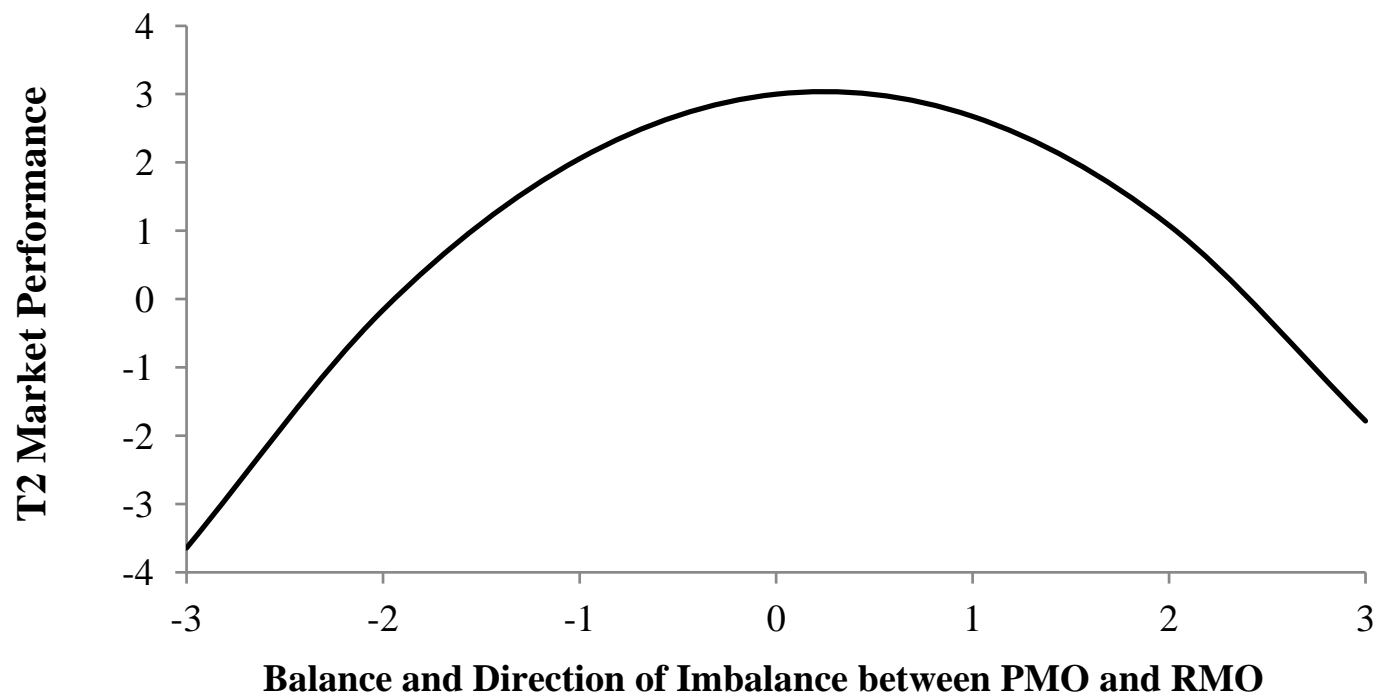

$(\mathrm{PMO}<\mathrm{RMO})$

$(\mathrm{PMO}>\mathrm{RMO})$

Panel B: Shape of the response surface along the symmetry line

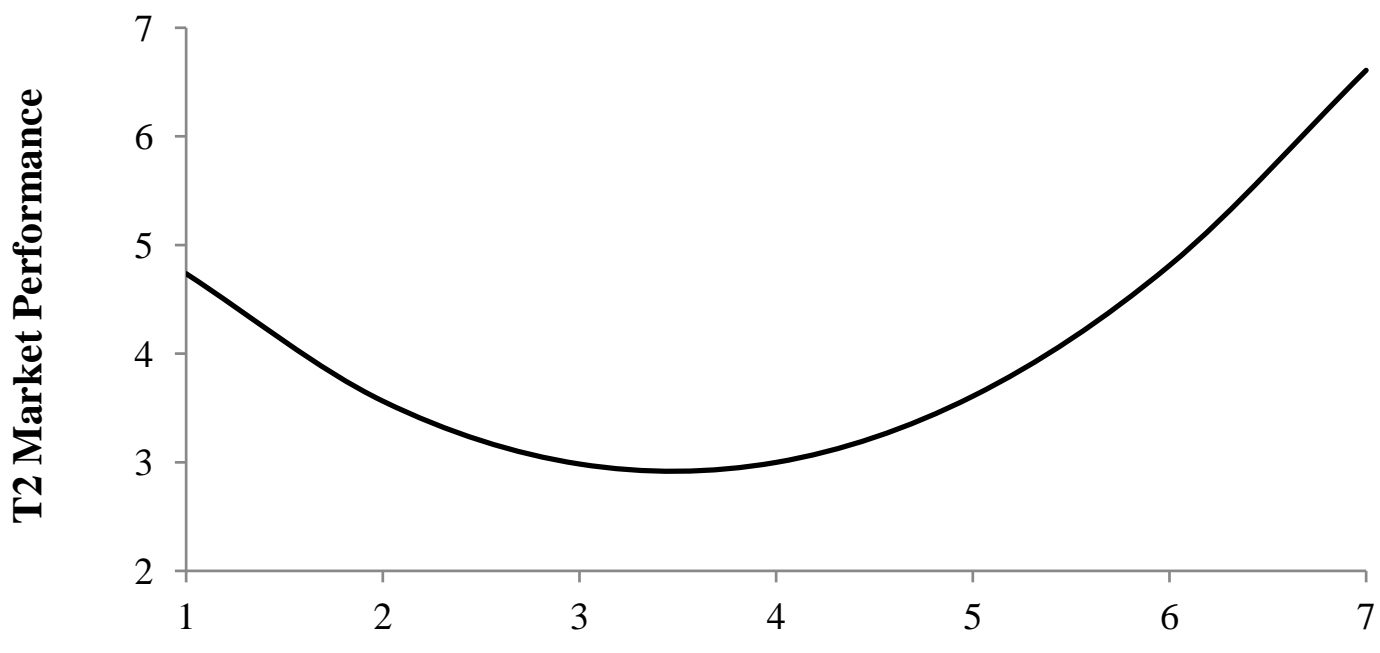

Level of Balance between PMO and RMO

$$
(\mathrm{PMO}=\mathrm{RMO})
$$

Note $: \mathrm{PMO}=$ proactive market orientation, $\mathrm{RMO}=$ responsive market orientation. Both variables have a range from 1-7 and are centered at their scale midpoints in Panel A. 


\section{APPENDIX \\ Key constructs and measurement items}

Variables and Items

Loading

Proactive Market Orientation

We help our customers anticipate developments in their markets. $\quad .70$

We try to discover additional needs of our customers of which they are unaware. $\quad .72$

We brainstorm on how customers use our products and services.

We search for opportunities in areas where customers have difficulties expressing their needs. $\quad .81$

We extrapolate key trends to gain insight into what customers will need in the future. $\quad .70$

We help our customers anticipate developments in their use of our products and services. $\quad .69$

We incorporate solutions to unarticulated customer needs in our new products and services. $\quad .70$

We work with lead users to recognize the needs of the majority of customers in advance. $\quad .68$

\section{Responsive Market Orientation}

We constantly monitor our level of commitment and orientation to serving customer needs. $\quad .80$

Our strategy for competitive advantage is based on understanding customers' expressed needs. $\quad .82$

We measure customer satisfaction systematically and frequently.

We are more customer-focused than our competitors. $\quad .96$

I believe this business exists primarily to serve customers. $\quad .72$

Our company's business objectives are driven by customer satisfaction. $\quad .96$

Data on customer satisfaction are disseminated at all levels in this company. $\quad .64$

$\begin{array}{ll}\text { Market Performance } & \text { T1 / T2 }\end{array}$

In the last two years relative to your competitors, how has your SBU performed with respect to:

$\begin{array}{lr}\text {....sales growth. } & .79 / .90\end{array}$

...increase in market share. $\quad .84 / .89$

$\begin{array}{lr}\text {...profitability. } & .71 / .88\end{array}$

\begin{tabular}{lr}
...return on investment. & $.91 / .91$ \\
\hline
\end{tabular} 